Thorax 1987;42:903-904

\title{
Comparison of bronchograms after instillation of contrast medium via fibreoptic bronchoscope and nasal catheter
}

\author{
D C CURRIE, J M GOLDMAN, P J COLE, B STRICKLAND
}

\author{
From the Host Defence Unit, Department of Thoracic Medicine, Cardiothoracic Institute, and the Department \\ of Radiology, Brompton Hospital, London
}

\begin{abstract}
Bronchography using a fibreoptic bronchoscope to instill the contrast medium is increasingly popular, with an estimated 526 procedures performed in the United Kingdom in 1983. ${ }^{12}$ The qualities of bronchograms obtained by this and by conventional techniques have not been compared. We organised a retrospective study to compare the results of bronchography via a fibreoptic bronchoscope with those obtained via a nasal catheter.
\end{abstract}

\section{Methods}

Bronchograms from 40 consecutive caucasian patients, who underwent bilateral bronchography from November 1984 to March 1986 to establish the presence and extent of bronchiectasis, were assessed retrospectively by an independent pulmonary radiologist. He completed a standard form designed to determine the quality of each bronchogram. Twenty patients had bronchography performed via a fibreoptic bronchoscope and, by coincidence, 20 had bronchography via a nasal catheter. Segments of the bronchial tree inadequately filled by contrast medium, segments with bronchiectasis, and lobes with a considerable excess of mucus were noted. The degree of inspiration achieved, the technical quality of the radiographs, the comprehensiveness of the series of films, any problems of interpretation caused by the presence of the fibreoptic bronchoscope or nasal catheter, and a visual analogue score $(0-100 \mathrm{~mm})$ of the overall quality of each bronchogram were also recorded. The fibreoptic bronchoscope or nasal catheter was visible on each set of films.

Bronchography was performed in a similar manner in the two groups except for the use of either fibreoptic bronchoscope or nasal catheter. Patients were given atropine $0.6 \mathrm{mg}$ and usually papaveretum one hour before the procedure. Physiotherapy was prescribed if indicated. Each procedure was performed by an experienced pulmonary radiologist (10 by one consultant radiologist) or by a radiologist under experienced supervision (13 by one senior registrar), with the assistance of a radiographer and in the

Address for reprint requests: Dr D C Currie, Host Defence Unit, Cardiothoracic Institute, London SW3 6HP.

Accepted 2 February 1987 case of the group examined by fibreoptic bronchocope also a physician. Both fibreoptic bronchoscope and nasal catheter were passed nasally under local anaesthesia (lignocaine). In the group examined by fibreoptic bronchocope visual inspection of the bronchial tree and aspiration of secretions were routine. Before instillation of the contrast medium (aqueous propyliodone-Dionesil, Glaxo) the fibreoptic bronchocope or nasal catheter was positioned in the main bronchus with the right side always examined first. If incomplete filling obviously occurred during the procedure, the fibreoptic bronchocope or nasal catheter was repositioned to allow more local filling. A series of radiographs was taken while the patient was asked to refrain from coughing. The patient was then encouraged to expectorate the contrast medium and, occasionally, post-tussive films were taken. Afterwards physiotherapy was performed routinely.

Mann-Whitney U tests, $\chi^{2}$ tests, and Kendall's rank correlations were used to assess the statistical significance of differences between the two groups.

\section{Results}

The patients in the two groups were similar as judged by age, sex, extent of bronchiectasis, $\mathrm{FEV}_{1}$, and the grade of radiologist (consultant or senior registrar) who performed the procedure (table). There were no statistical differences between the two groups for the visual analogue scores of the overall quality of bronchograms, number of inadequately filled segments, and lobes with excessive mucus (table). There was a wide range of visual analogue scores $(4-99 \mathrm{~mm})$, which were inversely correlated with the number of inadequately filled segments $(r=-0.38, p<0.001)$. The visual analogue score was not correlated with age, FEV 1 (only six of 40 patients had an $\mathrm{FEV}_{1}$ below $80 \%$ of the predicted value), extent of bronchiectasis, number of lobes with excess mucus, or the grade of the radiologist or an individual radiologist. Inadequacy of filling was correlated with excess mucus $(r=0.5, p<0.001)$, extent of bronchiectasis $(r=0.33 \mathrm{p}<0.001)$, and increasing age $(r=0.24, p<0.02)$. Excess mucus was correlated with bronchiectasis $(r=0.55, p<0.001)$ and increasing age $(r=0.39, p<0.001)$, and bronchiectasis with increasing age $(r=0.39, p<0.001)$. The presence of the fibreoptic bronchocope or nasal catheter in the bronchial tree never obscured important features. The degree of inspiration was always adequate. 
Patients' characteristics and quality of bronchography performed with a fibreoptic bronchoscope (FOB) or a nasal catheter $\bar{O}$ $(N C)$ : means with ranges in parentheses except where otherwise indicated

\begin{tabular}{|c|c|c|c|c|c|c|c|c|c|}
\hline & $\begin{array}{l}\text { Sex } \\
(M: F)\end{array}$ & $\begin{array}{l}\text { Age } \\
(y)\end{array}$ & $\begin{array}{l}F E V_{1} \\
\left(\% \text { pred }^{3}\right)\end{array}$ & $S R$ & $\begin{array}{l}\text { BR* } \\
\text { (segments/ } \\
\text { patient) }\end{array}$ & $\begin{array}{l}V A S \\
(\mathrm{~mm})\end{array}$ & $\begin{array}{l}\text { Inadequate } \\
\text { fllingt } \\
\text { (segments/ } \\
\text { patient) }\end{array}$ & $\begin{array}{l}\text { Mucus } \\
\text { excess } \\
\text { (lobes/ } \\
\text { patient) }\end{array}$ & $T E C$ \\
\hline $\begin{array}{l}\text { FOB }(n=20) \\
N C(n=20)\end{array}$ & $\begin{array}{l}8: 12 \\
8: 12\end{array}$ & $\begin{array}{l}39(17-65) \\
38(21-65)\end{array}$ & $\begin{array}{l}96(27-120) \\
91(35-145)\end{array}$ & $\begin{array}{l}16 \\
12\end{array}$ & $\begin{array}{l}1.45(0-10) \\
2.15(0-11)\end{array}$ & $\begin{array}{l}67(4-95) \\
75(28-99)\end{array}$ & $\begin{array}{l}2.5(0-14) \\
2.9(0-10)\end{array}$ & $\begin{array}{l}2 \cdot 0(0-6) \\
2 \cdot 25(0-6)\end{array}$ & $\begin{array}{l}3 \\
2\end{array}$ \\
\hline
\end{tabular}

*Fourteen patients in the fibreoptic bronchoscope group and nine in the nasal catheter group had no evidence of definite bronchiectasis of the bronchograms.

tTen bronchograms from the fibreoptic bronchoscope group and 12 from the nasal catheter group showed complete filling of the bronchial tree with contrast medium.

SR-Number of patients whose bronchography was performed by a senior registrar (the remainder were done by a consultant);

BR-extent of bronchiectasis on bronchogram; VAS - visual analogue score (0-100) of overall bronchogram quality; TEC - number of bronchograms of substandard technical quality.

\section{Discussion}

The quality of bronchograms was similar in the two groups in our study as judged by visual analogue scores. Many patients who undergo bronchography with contrast medium introduced via nasal catheter also undergo bronchoscopy to exclude a foreign body or endobronchial lesion, or to reveal the cause of haemoptysis. Performing both investigations as a combined procedure (as carried out in half the patients in this study) does not compromise the quality of bronchogram and avoids more than one invasive, unpleasant investigation. Use of the bronchoscope allows excess mucus to be cleared by suction and prevents performance of a potentially unsatisfactory or unnecessary bronchogram if the bronchial tree is full of mucus or an unsuspected cause of the symptoms is discovered. Bronchial secretions may also be obtained for microbiological culture.

Despite preliminary physiotherapy, a well preserved $\mathrm{FEV}_{1}$ in most patients, and a team approach to the procedure, the quality of bronchograms in both groups wasvariable, but this was not directly related to age, extent of bronchiectasis, excess mucus, or the method used.

As bronchography via a fibreoptic bronchoscope has advantages over use of a nasal catheter and provide bronchograms of similar quality we conclude that the former method is preferable.

\section{References}

1 Simpson FG, Arnold AG, Purvis A, Belfield PW, Muers MFi Cooke NJ. Postal survey of bronchoscopic practice by physicians in the United Kingdom. Thorax 1986;41:311-7.

2 Flower CDR, Shneerson JM, Bronchography via the fibreoptio bronchoscope. Thorax 1984;39:260-3.

3 Cotes JE. Lung function: assessment and application in medicine 3rd ed. Oxford: Blackwell Scientific Publications, 1975. 